\title{
Digital Competences of Maria Grzegorzewska Academy of Special Education Students - Method and Results of a Survey
}

\author{
Miłosz W. Romaniuk
}

\begin{abstract}
Author analyses the use of new technologies by the pedagogy students from the generation of digital natives focusing on using the functions of mobile electronic devices and basic functions of Internet. Data has been collected with Google Forms. They allow to collect the data very quick, to see the responses immediately and to export the data to a spreadsheet. The aim of the study is to determine the level of student's competence on the chosen field of information technology. Research shows that students have lower skills than they declare. Author advocates that this situation needs to be improved.
\end{abstract}

Keywords - information technology, computer skills, students, new technologies, Internet, computer, smartphone, Google Forms

\section{INTRODUCTION}

$\mathbf{C}$ OMPUTERS in different forms are ubiquitous. They assist humans everywhere - at home, at school, at work or even on the street. They became a constant part of the environment. This requires a man to have an adequate knowledge and skills to use their capabilities competently to meet human needs and doing it effectively and safely at the same time. Today's students have grown up in a world where wireless Internet, smartphones and powerful computers with good software were already present. They should smoothly function in a world full of electronic equipment. The article is a report of the survey conducted among students of the Academy of Special Education. They were asked about their competences in the use of stationary and mobile electronic devices such as computers, laptops, netbooks, tablets and smartphones.

\section{GOOGLE ForMS AS AN EFFICIENT METHOD OF COLLECTING} DATA

Conclusions drawn and collected data presented in this article are the result of research analysis prepared and conducted by the author. The author, wanting to make use of modern methods of collecting data, used Google Forms as a method of collecting data. Google Forms is a tool that allows to prepare a questionnaire, with which you can examine the respondents either directly or remotely. It was established in

M.W.Romaniuk is with the Maria Grzegorzewska Academy of Special Education in Warsaw, MRomaniuk@aps.edu.pl the second half of 2008 and since then has been gradually modernized. At this point, it allows you to prepare an expanded questionnaire that lets the researcher to collect data from respondents easily. [1]

Preparing your own form using Google Forms is simple and possible for every researcher. All options are understandable and their handling is intuitive. The tool allows to include in the form all sorts of questions. Available types include open questions that allow respondents to write a shorter or a longer statement, the single choice and multiple choice questions, selecting answers from the dropdown list, selecting the answer on the varying range scale (minimum range scale is from 1 to 2 , and the maximum from 0 to 10). It also allows to choose the date, time and duration of the activity. In addition, you can design question in the form of a grid containing questions in rows and answers to mark in columns. The tool also provides an option allowing to divide the form to pages in order to group questions or arrange them thematically.

Working with Google Forms should begin with naming the form and entering its description including information for respondents. Then you can proceed to questions preparing phase. After setting the kinds of single question its content should be formulated and entered in the appropriate box. Google Forms allow to include the help text for the respondent, edited by the author and displayed under the question during survey, providing the examined the information how to respond to the question. During the form creation process author can take advantage of additional options such as adding a progress bar at the bottom of the form or mix the order of questions so that each respondent will answer them in a different order. The tool allows to collect the responses also from people who do not have a Google account. There is an option to reduce the amount of fillings questionnaire to one per person, but in this case respondents must have a Google account and have to be logged in during taking part in the survey. Each question can be marked as mandatory to fill. If one misses this question, the tool does not allow the respondent to go to the next page or send the form as questionnaire is not completed. This makes the respondents to carefully respond to questions. Thanks to this, researcher can avoid dealing with the problem of missing data.

Most kinds of questions mentioned before takes into account the possibility of applying some advanced settings. In open questions and multiple choice questions Google Forms allows you to validate the entered data. In open questions exact type 
of answer can be set by the author. This may be a number or text. If the number is set, the author of the form may force the respondent to provide a number greater than stated by the author, greater than or equal to, less than, less than or equal, equal, different from that given by the author, located within the range specified by the author or going beyond this range, integer or just numerical value. In the case of the text, the author can limit the respondent's answers to those containing the desired word (or not including it). Form of the text answer can also be set to the form of an e-mail address or a URL. Single choice questions, multiple choice ones, dropdown list and the question in a grid give the author the opportunity to select or to randomize the order of displayed answers. Single choice questions and multiple choice questions allow, in addition to placing predefined answer options, the addition of the "other" answer. After selecting it, the user can enter his own answer. In addition, single choice questions and dropdown lists allow to use the cafeteria and transfer the respondent to specified by the author of the form page of questions containing those which are not available for people who have not indicated the desired response. Other configuration options available for the author and depending on the form of reply given by the respondent in the multiple choice questions are moving to the next page of questionnaire or even to its conclusion and ending it immediately. Advanced settings for multiple-choice questions allow the author to decide if the respondent has to choose at least, at most or exactly as many answers as instructed by the author. During creation of a question in the form of a grid, the author may prevent the user from selecting more than one answer in the column (normally there is a limit of responses to one per line). When asked about the date, the examined indicate month and day, and the author may supplement the question of year and precise time. The question of the specific time can be converted to a question about the duration of examined activity.

During finishing the preparation of the form author has a several options to choose that can be provided to the respondent who finished filling in the questionnaire. The tool allows to view a text confirmation about the correct saving and sending the response, display a link that, when clicked, enables to reset the questionnaire and start to complete the survey from the beginning and dispatch as another response. The author may also provide the respondents a link to the results of the survey and let the examined people to take a look at them. In addition, the tool allows the possibility to enable the option that lets the respondents to edit their responses after sending the form.

Google Forms enables to deliver the finished survey to respondents in many different ways. This may be a link sent via email or shared through social networking sites. Google Forms support Google+, Facebook and Twitter. In addition, it allows the author to define co-workers, which can be given the right to edit the form. As a result, several people at once can work over one questionnaire. Moreover, link generated and leading to the form can be shortened, which makes it much more convenient to rewrite in the address bar of the Web browser when the URL is displayed using a projector or distributed to respondents in printed form.

Answers are stored in a spreadsheet located in the author's Google Drive after completing the questionnaire by each respondent. Author can view previously collected data any moment. This is possible in two ways. The first option is a summary of the responses displayed on a page on which the answers given by respondents are presented in charts described in absolute numbers and percentage of answers. The second option takes the user to a web application Google Sheets displaying raw results in a spreadsheet. Answers are displayed in rows. There are labels of questions in the first row. Each column contains answers to the next question. The first column contains a timestamp of filling out the form by a particular respondent which is an additional valuable information for the researcher.

When researcher finds that he has received sufficient number of answers, he can disable the option of accepting the following replies. It will cause that no additional person will be able to fill in the questionnaire. Accepting answers can be switched on again at any time. A complete database containing all answers can be exported and saved on hard drive in several ways. It saves automatically to your Google Drive's in the form of xls file by default. You can move it in this format to disk or export it to ods format, which is an OpenOffice workbook file. The results form can also be saved in PDF file, not editable but versatile and easy viewing format. Those who need other forms of exported data can use the option of saving in csv (comma separated values) or tsv (tab-separated values). The last option of saving is to store the results of the survey in the form of an archived web page (zip). The variety of database export options allow easy import to statistical programs like SPSS in purpose of the subsequent advanced analysis of collected data.

\section{CONTEMPORARY STUDENTS AS DIGITAL NATIVES}

The vast majority of current undergraduate students are persons born in the years 1993-1995. They belong to a generation that was born and grew up in the world of digital age. They are referred to as the Digital Natives. This concept was established in 2001. Marc Prensky, an American academic teacher dealing with the issues of education and training of contemporary young people, also using new technologies, proposed and popularized this term. [2] Prensky defines Digital Natives as persons who are fluent in the language of digital world and the Internet as easily as if they spoke their native language. All those who were not born in the digital age, but adapted to the new conditions introduced by it, were called Digital Immigrants by Prensky. Regardless of their digital competences, "foreign accent" can be heard among people who did not grow up in the digital world. [3]

A significant part of the $\mathrm{Y}$ generation members, also called Millennial Generation, are also Digital Natives. According to William Strauss and Neil Howe, two American historians, generation Y members are people born between 1982 and 2004. The name "millennials" comes from the year 2000, when the first born generation members reached adulthood. Generation is a generation called $\mathrm{Y}$ (Why) because its members have a tendency to ask the question "Why?" very often. [4]

Research conducted by McCrindle, the Australian company dealing with the problem of understanding societies, indicate the rise of a new generation. According to researchers from McCrindle, Generation Z are people born in the years 1995- 
2009. [5] They also are Digital Natives. Due to the fact that they grew up in a world of even more advanced technology than Generation Y, they are different from its representatives. They have a different language, use the media differently, they learn in other ways, other things motivates them and other become their authority. [6]

The periods of time, in which people have to be born to belong to a particular generation, are fluent. They differ, depending on the author undertaking the issue of membership of people in the generations and on the country in which members of that generation are living. Regardless of the differences in defining boundaries between generations and moments of the transition from one generation to another it can be certainly stated that the current generation of students belongs to the generation of Digital Natives. Therefore, they should have adequate competences to use available modern technology efficiently and unleash its capabilities effectively. The author conducted the study, which aimed to check the level of digital competences of Academy of Special Education students regarding the particular use of mobile devices and the Internet.

\section{APPLIED TOOL AND EXAMINATION PROCEDURE}

The author has prepared a questionnaire consisting of 27 questions which were divided into 4 groups. The first one concerned some aspects of the use of computers and mobile devices. It included questions about the amount of time spent using computer or smartphone, the amount of time spent per day on the Internet, the number and type of owned electronic devices, number of different passwords for accounts and devices, backup frequency, type of data chosen to backup and method used to transfer the data. Students were also asked to assess their digital competences connected with computers and new technologies. In addition, respondents had to mark on the list containing different technologies (e-mail, chat, online drive, cloud applications, WebQuest, QR code, NFC, geolocation, electronic banking, backup, augmented reality, remote desktop, data encryption) if they know a particular technology and whether they use it or not.

The second group of questions were related to the computer in the form of a desktop computer, laptop or netbook. It contained questions about the operating system, the way of using a computer, its password protection and the frequency and method of software and system updates.

The third group of questions related to the type of mobile devices like smartphones, mobile phones or tablets. Among them there were questions about the operating system, the way of using the devices, used applications, exploited protection and frequency and way of updating the software and the system.

The fourth part of the questionnaire included demographics, containing questions about gender, year of birth, place of origin and occupation.

The study was conducted among people studying pedagogics at the Maria Grzegorzewska Academy of Special Education in Warsaw. Students were asked to complete a questionnaire during the course of Information Technology lecture. A link to the survey was delivered to the respondents in a text file. Students were asked for the greatest honesty when answering before starting to complete the survey. The author have not had to be present during the examination of each group thanks to the electronic form of the survey. Many people were examined by the author's associates, who were sent the link to the survey and were provided with basic instructions on how to carry it out. There were no problems with running the survey or the filling of the form reported during carrying out the research.

The data for the study were collected for one week, from February 26th to March 5th in 2015. There were 135 people that took part in a survey. Among them were $90,4 \%$ of women (122) and 9,6\% of men (13). This distribution is characteristic for participants in educational and pedagogy studies. Threequarters of respondents were born in $1995(73,3 \%, 99$ persons), one out of eight in 1994 (12,6\%, 17 persons), 6,7\% in 1993 (9 persons), one person in $1996(0,7 \%)$ and the remaining $6,7 \%$ in $1987-1993$. Such distribution is due to the natural process of education, in which the high school students usually go to college. Some people are studying in part time, which explains the presence of older respondents in the database. More than half of the respondents (59\%, 73 persons) come from small towns (up to 50 thousand inhabitants) and rural areas. When the students were filling the questionnaire they were also observed by the author, who noticed that the respondents are very often not sure of the size of the city of their origin. $82.9 \%$ of respondents (112 persons) does not work and just study. 4 people work as nannies, another 4 as telephone consultants, 2 as receptionists, 2 as saleswomen. Other respondents reported occupations such as animator, interviewer, barista, waitress, technical worker or secretary.

\section{STUDENTS OF PEDAGOGY AND NEW TECHNOLOGIES - THE SURVEY RESULTS}

Respondents asked about the daily amount of time spent using a computer or with a mobile phone or smartphone in their hands estimated it from two to eight hours. $10 \%$ of examined people use electronic devices for 2 hours per day, $10 \%$ for three hours a day, $15 \%$ for 4 and 5 hours a day, $10 \%$ for six hours a day and $7 \%$ for 7 and 8 hours per day. Interestingly, $10 \%$ of people declared that they use computers or smartphones for over 12 hours each day. They are constantly on-line, checking what is new, updating their statuses, messaging etc. Such frequent use of electronic devices results in time spent on the Internet. $75 \%$ of people spend from 2 to 6 hours on-line per day. $15 \%$ uses the Internet for 2 hours per day, $25 \%$ for 3 hours, $10 \%$ for 4 hours, $15 \%$ for 5 hours and $10 \%$ for six hours. The correlation between the time the use of electronic devices per day and daily time spent on the Internet is very high and statistically significant $(\mathrm{r}=$ $0.761 ; p<0.01)$. In addition, half of the respondents has two electronic devices, $30 \%$ of them use three, and $15 \%$ use four computer-like devices (desktop computer, laptop or netbook), smartphone or tablet. The most commonly used devices are mobile ones. $92 \%$ of respondents use laptops, $85 \%$ of them use smartphones and 46\% use tablets. Only 30\% use desktop computers. Not a single person using desktop computer has declared it as the only device they are using. Only $19 \%$ continues to use ordinary mobile phones. This coincides with the global proportions of the amount of standard mobile phones based on the amount of smartphones. [7] 
So intense contact with electronic devices and a large number of them located in the direct vicinity of the respondents should result into growing level of their digital competences connected with using those devices. Students were asked for an individual assessment of their computers and new technologies competence level. $40 \%$ of respondents identified it as average, at $20 \%$ as rather low, and $30 \%$ as rather high. Correlations between the assessment of their own competences and the number of hours of use of electronic devices per day $(\mathrm{r}=0.241 ; \mathrm{p}<0.01)$ and daily time spent on the Internet $(r=0.188 ; p=0.029)$ are weak but significant. There is no correlation between the number of owned electronic devices and time spent using them, time spent online and self-assessment of digital competences. Analysis of answers to questions about specific actions performed on computers and smartphones, however, indicate overestimation of respondent's competences. This is a fact confirmed by observation of respondents led by the author during conducting classes of Information Technology.

$40 \%$ of respondents do not back up their files and $35 \%$ do it once a year. Only $10 \%$ of respondents do the backup regularly, once a week or more frequently. There is no correlation between the stated level of competence and the frequency of backup. Less than half (45\%) of the respondents backs up their documents and only $19 \%$ protect themselves against the loss of contacts like phone numbers and e-mail addresses. $92 \%$ of respondents use pen-drives as a way to transfer their data and as a storage space. $60 \%$ use memory cards. Only $15 \%$ use the Internet drives and external drives. Convenience of using a small data carriers make users forget about disadvantages followed by their size, structure and quality of those devices. The risk of data loss or risk of losing a small thing like pendrive or memory card is larger than that risk of breakdown or losing the external drive. As author's observations made during conducting classes of Information Technology indicate, only a small percentage of respondents use Internet drives, despite of student's indications in the survey. The reason is a lack of awareness of their existence and unwillingness to learn the seemingly complex activities needed to handle them. Interesting is the fact that as much as $15 \%$ of respondents still rely on dying standards of CDs, and $10 \%$ use DVDs as a way to transfer their data.

While the vast majority of people use mobile devices for entertainment (Facebook 93\%, Messenger 80\%, listening to music $88 \%$ ) there are still very few respondents who use the capabilities of their smartphones and tablets to do "serious" activities. Only $35 \%$ of people use the application to operate a bank account, 18\% synchronize their calendar between different devices and $9 \%$ are able to wirelessly connect smartphone to computer. $30 \%$ still does not protect their phone with password, PIN or pattern. 30\% does not update the system software or phone applications and $10 \%$ declare that they are unable to do so.

Trends are similar for computers. 36\% do not passwordprotect their computer. $26 \%$ is not up to date with updates of computer programs and $16 \%$ are not aware of whether their programs and system is up to date. Only $60 \%$ believe that they are up to date with updates of their electronic devices. There is no correlation between the stated level of competence and the use of computer or phone protection against unauthorized access. There is also no correlation between neither time spent daily using electronic devices nor time spent daily on-line and password protecting the computer or mobile devices.

\section{SURVEY RESULTS AND DISCUSSION}

By analyzing the data obtained from the survey and also from observations made during the classes of Information Technology author acknowledges that the competences of students on the use of computers and mobile devices are not high enough. As representatives of the generation of Digital Natives students should not be limited only to the efficient use of entertainment related functions of their devices. In this case, powerful computers and smartphones are brought to the role of expensive gadgets. Qualified citizen of digital world should also be capable of using constantly increasing abilities of computers to organize reality around them and to encourage self-development. Otherwise, it may lead to a situation in which the device will control their users, inter alia, through the mechanisms of addiction.

Non-negligible is also a safety issue. Electronic devices represent a link with the virtual world for humans. The user, who is not capable of providing himself an adequate protection and cannot protect his digital equipment becomes vulnerable to all sorts of dangers like identity theft, privacy violation, data loss or money theft from bank account to mention but a few. To minimize the chances of a similar type of situation it is needed to prepare young people to living and functioning in the digital world. The problem especially concerns young people who want to study education and pedagogy as they will become future teachers and educators. They are meant to educate future generations increasingly rooted in the Internet world. So they have to remember that with their actions they have to set a good example of competent and safe functioning in the digital world for their pupils. In another case, they will raise a defenseless generation of digital illiterates, unprepared for any challenges of Internet and digital modernity.

There has been a shift of emphasis in using electronic devices far in the direction of entertainment. Unskilled users commit gross negligence in security issues and have gaps in knowledge and practical skills associated with advanced handling of electronic devices accompanying a man at his every step. They also lack the desire to expand that knowledge and acquire new skills. This may result in a reduction of intellectual potential of youth, progressive stratification of society and the division to competent minority and limited to the entertainment and simple functions handling majority. This will give ample room to maneuver for people who will use this conjuncture for evil preying on the defenseless, unskilled users.

Analyzing the research you can find that students have certain competences on the use of electronic devices, but they are strongly shifted towards applications and activities related to entertainment. Still too few people are able to care for their electronics by keeping it updated. Too many people fail to protect their devices adequately. Being an educator, which means being constantly observed by pupils and bearing responsibility for younger generations on their shoulders is an extremely obliging choice. Hence, it is necessary to deepen the research conducted by the author in order to create a complete profile of competences of generation entering the labor market. In addition, it is necessary to establish a training program for 
school children, during which they will acquire real and tested knowledge and skills related to security in the digital world and the powers to use the electronic devices not only for entertainment. Young people from the earliest age should be adopted to lifelong learning and acquiring skills needed for the efficient functioning, and not just for the survival of life or vegetation. It is easy for unprepared people to shallow their thinking, choose the easy way of entertainment and become only the consumer of simplified content that is dominated by media messages in the digital world. [8] It is necessary to raise the level of teaching during computer classes in elementary and middle schools. It is important to place greater emphasis on the transfer of specific skills applying to the functioning inside the digital world. Otherwise, we risk a digital illiteracy, shallowing of thinking and complete vulnerability in the face of any virtual (but only in name) danger. [9]

\section{MISJUDGMENT OF OWN COMPUTER LITERACY AND ITC KNOWLEDGE - ITS CAUSES AND CONSEQUENCES IN X AND Y GENERATIONS}

There is no clear definition and scientific confirmation of reasons of incorrect self-assessment of competencies related to the handling of personal electronic devices among students. It would seem that the technological literacy level of the generation growing up in the digital world will be high. This level is, as studies show, too low. This raises the question of why students do not have these skills. Checking should begin with asking which competences students should achieve during the previous stages of their education.

Analysis of the teaching programme which defines educational goals to be achieved after the completion of the first two stages of education implemented during computer classes in primary school indicates that the surveyed students have a lot of skills mentioned in the programme. Unfortunately, still glaring deficiencies are noticeable, especially in the terms of safe use of a computer. These are, in particular, not understanding the messages sent by programs, failure to properly save and store files and a limited computer vocabulary. These skills should be learned from the computer science classes in elementary school. To get a positive final grade computer class student must prove that he has achieved its goals of education. The author considers this a sufficient indicator of the fact that the primary school pupil has the basic skills on the computer.

The third stage of education, conducted in the secondary school on the subject, called Information Technology, includes competencies that students also have to a large extent. Unfortunately, the author's observation leads to statement that students cannot handle even a text editor, not to mention a spreadsheet or Web page editor to greater level than very basic one. This forces academic lecturers need to make up overdue material, because without such basic skills students are not able to properly prepare a research tool or format the thesis in a text editor or develop their research in a spreadsheet.

Students do not have a habit of backing up their data or to protect them in a more advanced way. Thus they become easy victims of identity theft, as well as they expose the fruits of their labour to loss. It is difficult to convince them to use automatic backup tools, because in their perception they are unnecessary. Students do not want to learn how to use them, and think that the chance of data loss is too small. In the era of the planned obsolescence of products it is extremely reckless approach. An unflinching belief in the reliability of electronic equipment confronted with its failures in the most unexpected and inconvenient moments led to creating the saying that computer users are divided into those that do backup and those who will be doing it.

The fourth stage of education is carried out in high school and is divided into two ranges, basic and extended. If it is assumed that anyone who graduated from high school should have at least the skills described in the basic scope of the subject, it can be firmly stated that the surveyed students do not have a large number of them. Examples of skills not mastered by students are editing raster and vector graphics, file conversion, making movies, preparation of documents with complex structure, advanced formatting a spreadsheet, creating a database and working with it, preparing non-linear and complex multimedia presentation or, mentioned before, designing and developing a website.

The results indicate that respondents use their electronic devices mostly for entertainment. Those who use computers to learn, improve their skills or to broaden their interests are rarity among them. These disturbing trends are the more alarming when occurring in respondents who are after all candidates for future teachers. Having no well-established computer knowledge at the secondary level between people that will teach youth even more strongly rooted in the digital world is reprehensible and can be fraught with consequences. Changing ways of transferring knowledge forces the teachers further training in the use of ICT in teaching. This, however, requires a solid basis, which are basically standard among professionals. Otherwise, the teacher will not be an example for young people, will lose the authority, and will not educate his or hers students to have internal need or desire to deepen their knowledge in the field of computer science. This will nurture generations of digital illiterates, which will reduce the overall level of society.

Learning to solve problems in various fields using a computer is the essence of computer science. Citizens of the digital world, where the omnipresence of computers has become a reality must be properly educated to be able to use computers to a higher than the primary degree. The increasing computing power, disk capacity, speed or ease of use of electronic devices are to serve man, raise the level of his life and be an extension of human's mind. The ability to use computers is extremely important because it allows a man to push the boundaries of human capabilities and increase them. Misjudgement of own competences among students can lead to reluctance to their further education in this direction because of the apparent and false self-image as efficient computer user. As previously indicated, this can cause helplessness in the face of more demanding task than just using social networking.

Maturing young people entering adult life are spending more and more time with a smartphones in their hands. It is their basic tool for communicating with each other and with the rest of the digital world. However, it is important to teach them how to use the other possibilities of their electronic devices so from expensive toys they can become useful tools. Each successive generation will be more deeply rooted in 
electronics, computers, new technologies and virtual worlds. The priority is therefore to prepare them for life in the equivalent realities, real and virtual. However, one very important issue cannot be forgotten. While teaching computer competencies is important it is needed to remember that a person must be able to cope without the help of a computer. Turning own memory to electronic man loses his own identity, as it is the memory that creates it. If you omit this fact and leave everything to the computers it will be tantamount to making the next step on the road leading to the fall of man.

\section{REFERENCES}

[1] Grabowska E. (1989). Ankieta [w] Góralski A. red., Metody badań pedagogicznych w zarysie, Wyd. WSPS, Warszawa, s. 64-70

[2] http://www.marcprensky.com/ [dostęp 6.03.2015]

[3] Prensky, M. (2001). Digital Natives, Digital Immigrants, On the Horizon Vol. 9 No. 5, October 2001, MCB University Press

[4] Howe N., Strauss W. (1991). Generations: The History of America's Future, 1584 to 2069, Harper Perennial

[5] http://generationz.com.au/ [7.03.2015]

[6] http://mccrindle.com.au/resources/Generations-DefinedSociologically.pdf [7.03.2015]

[7] http://www.tabletowo.pl/ [dostęp 10.03.2015]

[8] Carr N., (2010). The Shallows. What the Internet is Doing to Our Brains, W. W. Norton

[9] Tapscott D. (2010). Cyfrowa dorosłość. Jak pokolenie sieci zmienia nasz świat, wydawnictwa Akademickie i Profesjonalne, Warszawa 